\title{
画像処理によるバレル研磨面の評価方法に関する研究*
}

\author{
加 藤 和 彦*1, 五百井 俊宏*1, 榎 本 畺 三*2
}

\section{Study on Visual Evaluation for Barrel Finished Surfaces}

\author{
Kazuhiko KATO*3, Toshihiro IOI and Shinzo ENOMOTO \\ *3 Department of Project Management, Chiba Institute of Technology, \\ 2-17-1 Tsudanuma, Narashino-shi, Chiba, 275-0016 Japan
}

\begin{abstract}
In this paper, an intelligent visual evaluation system using a neural network is developed in order to evaluate the barrel finished surfaces. It is well known that the surface integrity after barrel finishing depends on type of finishing machines, nature of the media and the compounds. The integrity of barrel finished surfaces, when different compounds were used, have typically been evaluated by visual inspection of expert workers. It is necessary to introduce the optical qualitative evaluation system instead of visual inspection in an automated inspection line. However, it is very difficult to evaluate the finished surface using image processing and/or other measuring equipment, because of complexity of data analyses for slightly different light reflection data among each finishing condition. As a result, not many papers have been published on the optical evaluation system for the barrel finished surfaces when different compounds were used. The objectives of the paper are to analyze the image of barrel finished surfaces using image processing, and to construct a neural network system which is able to evaluate the finished surface integrity. In this paper, it is found that features of barrel finished surfaces are decided by image analyses. As a result, it is possible to construct a neural network system composed of the finished surface image features as input layer and grades by the sensory test as output layer.
\end{abstract}

Key Words: Image Processing, Neural Network, Recognition, Product Evaluation, Visual Evaluation, Barrel Finished Surface

\section{1. 緒言}

バレル研磨機による仕上げ加工部品の表面性状は, バレル研磨機の種類, メディアやコンパウンドの種類 や装入量，そして研磨時間などの多くの因子によって 変化することがよく知られている. バレル研磨におけ るコンパウンドの役割は, 研磨面の潤滑や洗浄が主で ある.しかし，特に光沢仕上げにおいては，コンパウ ンドの種類によって加工面のツヤや色調などが微妙に 異なることが知られている，そのため，光沢仕上げ部 品や装飾品等の研磨においては，コンパウンドの選定 が極めて重要な加工条件の因子の一つとなっている.

バレル研磨後のワークの仕上げ加工面評価は, 従 来, 熟練作業者の目視評価にほとんど依存している. しかし，その評価は，定性的，主観的，不安定であり， 作業者の評価能力に強く依存することが問題となって いる.また，目視評価と共に光沢度による定量的評 価も行われているが, その測定方法や測定速度がイ

\footnotetext{
* 原稿受付 2006 年 8 月 4 日.

*1 正員, 千葉工業大学社会システム科学部(更 275-0016 習志 野市津田沼 2-17-1).

*2 千葉工業大学社会システム科学部.

E-mail : kato@sky.it-chiba.ac.jp
}

ンライン自動検査への実用化に適していない問題 もある．画像処理によりバレル研磨後の仕上げ加工面 評価を定量的に行うことができれば，コンパウンドの 化学成分やその配合率と表面性状との相関特性を把握 することが可能となるため, コンパウンドの研究開発 において有効な指標となることが期待できる.さらに, 製造工程でのインライン自動検查も可能となる.

従来, 画像処理システムを利用した表面の評価法と して, 多くの有益な研究(1) (の)が報告されている.これ らでは，金属破断面 ${ }^{(1)}$, 異種金属材料の表面 ${ }^{(2)}$, きさげ 加工面 ${ }^{(3)}$, 摩擦摺動面 ${ }^{(4)}$, 鏡面 ${ }^{(5)}$, そしてへアライン仕

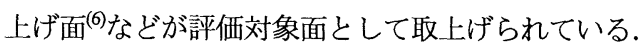
しかし，これらの画像処理を利用した表面評価に関す る研究では, 加工法や機械的加工条件の違いによる表 面特性の変化について検討したものが多く，バレル研 磨におけるコンパウンドの違いによっておこる表面性 状の評価については，ほとんど研究の対象とされてい ない.

そこで本研究では，従来の目視や光沢度による評価 方法と比較し, 安定性, 簡便性, 及びシステム構築の 柔軟性等の価值のある評価方法として，画像処理と二 


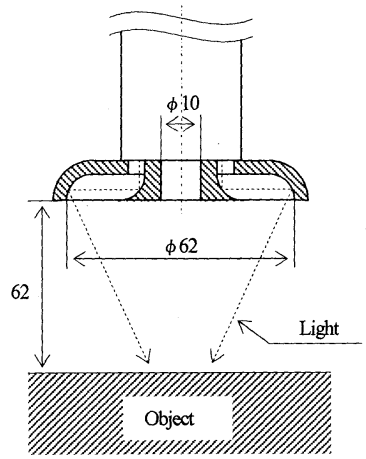

Fig.1 Lighting mechanism of a video microscope

ユーラルネットワーク（以下， NN と略記）を利用し た評価方法を提案した。まず，コンパウンドの違いに よるバレル研磨後の仕上げ加工面の特性を評価するこ とが可能な画像測定条件と画像処理アルゴリズムにつ いて検討した. 次に, 本研究で設定した各種画像特徴 量を統計解析し，その有効性について評価した. そし て,バレル研磨面からの画像特徴量を入力データとし, 目視評価によるグレード值を出力データとした NNを 構築し, その検証を行った.

\section{2. 実験装置及び方法}

本研究では, ビデオマイクロスコープを用いてバレ ル研磨後の仕上げ加工面を測定した。図 1 に，本研究 で用いたビデオマイクロスコープ(20 倍)の非接触式拡 散照明ヘッド部を示す.この照明へッドを用いること により，仕上げ加工面からの正反射光を軽減し，集光 効率を上げることができる. なお，本研究で用いたビ デオマイクロスコープによる画像倍率は, 15 インチモ ニタ上での横倍率である，表 1 に，本実験で用いたテ ストピースのバレル研磨条件を示す. 表 1 に示すメデ イアやコンパウンドの量, および研磨時間は, テスト ピース 1 個を作製するためのものである. 本実験に用 いたテストピースは，液体コンパウンド（L-1～L-12） 12 種類, 粉末コンパウンド (P-1〜P-8) 8 種類の合計 20 種類のコンパウンドを用いて作成した. コンパウン ドは，実用性を考慮して市販の仕上げ研磨用のものを 使用した．各コンパウンドの成分や配合率については 公表されていないが，界面活性剤が大きな役割を果た していることが推測される. 表 2 は，テストピースの 種類とその光沢度, 表面粗さ,および目視評価による ツヤと色調の評点を示す. 目視評価は， 7 名の熟練作 業者により 1 から 5 の数值尺度を使い，採点法(7)を用 いて評点を求めた。 なお，目視評価は，熟練作業者が 実用的な評価範用を充足するものを経験的に選択した
Table 1 Barrel finishing conditions of test pieces

\begin{tabular}{l|l}
\hline Material & SUS304, $\phi 28 \times 18 \mathrm{~mm}$, \\
& Glossiness: $613.8 \% \mathrm{Gs}(20)$ \\
& Surface roughness: $0.041 \mu \mathrm{m} \mathrm{Ra}$ \\
Machine & Centrifugal barrel \\
Media & Alumina, Spherical shape $\phi 3 \mathrm{~mm}, 3.5 l$ \\
Compound & Liquid 20g or Powder $50 \mathrm{~g}$ \\
Barrel finishing time & 20min \\
\hline
\end{tabular}

Table 2 Surface property of test pieces

\begin{tabular}{c|c|c|c|c}
\hline $\begin{array}{c}\text { Test piece } \\
\text { ID }\end{array}$ & $\begin{array}{c}\text { Glossiness } \\
\% \text { Gs(20) }\end{array}$ & $\begin{array}{c}\text { Surface roughness } \\
\mu \mathrm{m} \mathrm{Ra}\end{array}$ & $\begin{array}{c}\text { Grades of } \\
\text { gloss }\end{array}$ & $\begin{array}{c}\text { Grades of } \\
\text { color tone }\end{array}$ \\
\hline P-1 & 843.6 & 0.048 & 1.7 & 1.4 \\
P-2 & 778.8 & 0.050 & 1.4 & 1.2 \\
P-3 & 757.8 & 0.043 & - & - \\
P-4 & 749.4 & 0.046 & 0.7 & 0.8 \\
P-5 & 726.0 & 0.049 & 0.9 & 1.0 \\
P-6 & 699.0 & 0.051 & - & - \\
L-1 & 628.2 & 0.043 & 0.0 & 0.1 \\
L-2 & 598.2 & 0.042 & -0.1 & -0.1 \\
L-3 & 560.0 & 0.041 & -0.8 & -1.0 \\
L-4 & 551.4 & 0.046 & - & - \\
L-5 & 534.0 & 0.046 & - & - \\
L-6 & 527.4 & 0.045 & - & - \\
L-7 & 522.6 & 0.050 & - & - \\
L-8 & 520.8 & 0.046 & - & - \\
L-9 & 517.2 & 0.050 & - & - \\
L-10 & 505.2 & 0.048 & -0.7 & -0.8 \\
P-7 & 488.4 & 0.039 & - & - \\
L-11 & 469.2 & 0.045 & -1.3 & -1.3 \\
P-8 & 465.6 & 0.043 & - & - \\
L-12 & 401.4 & 0.044 & -1.7 & -1.3 \\
\hline \multicolumn{5}{|r}{}
\end{tabular}

Table 3 Experimental conditions

\begin{tabular}{l|l}
\hline Image size & 128 pixel $\times 128$ pixel \\
Gray level & 256Gradation \\
Element for shot & CCD image sensor \\
Light source & $100 \mathrm{~W}$ halogen lamp \\
Lighting & Oblique irradiation from multi-direction \\
Resolution $(\times 20)$ & $31 \mu \mathrm{m} /$ pixel \\
\hline
\end{tabular}

10 種類のテストピース (表 2 参照)を対象に行なった. この結果からツヤと色調は, 光沢度とほぼ相関関係に あることが分かった．表 3 は，本研究で設定した画像 測定条件である. 本研究では, 4 種類の照明へッドと 3 種類のレンズを組合せて 4 種類の測定系を設定し画像 測定を行ない，そのうち，NN による表面性状の識別 において最も良い結果が得られた測定系を採用した。

\section{3. バレル研磨面の画像解析}

3.1 画像解析 本研究では，バレル研磨面の方 向性がほとんど無い一様なテクスチャ性に注目し，そ の画像解析に統計的テクスチャ解析と濃度ヒストグラ ム解析を行なった. 画像特徴量としては, 統計的テク スチャ解析より 14 種類, 濃度ヒストグラム解析より 5 種類の合計 19 種類を設定した. また, ビデオマイクロ スコープで測定された RGB 画像データから 10 種類の 画像変換を行ないそれぞれの画像について画像解析を 行なった.

3.2 統計的テクスチャ解析方法 本研究では, バレル研磨面から得られる画像特徴量の再現性を高 


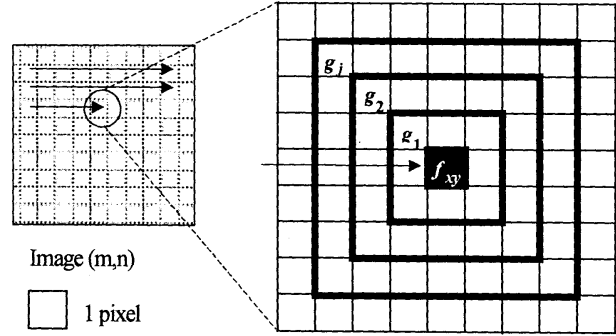

Fig.2 Principle of concentric frame image processing

めるために, バレル研磨面に対するカメラの測定位置 が，光軸を回転軸として回転した場合でもほぼ同一の 画像特徽量が得られる同心フレーム走查画像処理アル ゴリズムを開発した. そして，この手法を統計的テク スチャ解析の同時濃度生起行列と濃度-ランレングス 行列の算出に適用した.

図 2 に示す画像 $(m, n)$ 中の 1 画素を注目点 $(x, y)$ とし, その濃度を $f_{x y}$ とする. 注目点の同心フレーム領 域の平均濃度值を $g_{j}$ とすると, $g_{j}$ は式(1)で表すことが できる. 式（1）は， $j$ 番目までのフレーム内の濃度の 和を $j-1$ 番目までのフレーム内の濃度の和から引き, 画素数で割ることにより, フレーム平均濃度 $g_{j}$ を計算 する. 本研究では，同心フレーム領域を注目点画素を 中心とする正方領域の輪郭部とした.

$$
\begin{gathered}
g_{j}=\left\{\sum_{n=y-j}^{y+j}\left(\sum_{m=x-j}^{x+j} f_{m n}\right)-\sum_{l=y-(j-1)}^{y+(j-1)}\left(\sum_{k=x-(j-1)}^{x+(j-1)} f_{k l}\right)\right\} / 8 j \\
\text { ただし, } \quad(j=1,2,3, \cdots) \\
x, y: \text { 注目点座標, } f_{x y}: \text { 注目点の濃度, } \\
g_{j} \text { : 同心フレーム領域の平均濃度 }
\end{gathered}
$$

そして, 画像 $(m, n)$ の濃度 $f$ の画素から $j$ 画素だ け離れた同心フレーム領域の濃度が $g_{j}$ である確率 $P_{j}$ $\left(f, g_{j}\right)$ を要素とする同時濃度生起行列を求めた.

また, 注目画素と同じ濃度值が連続する同心フレー ム群をランと定義し，その連続数をランレングスと定 義した. そして, 画像 $(m, n)$ の濃度 $f$ 画素から同 濃度で $l$ フレーム続く頻度 $M(f, l)$ を要素とする濃度ランレングス行列を求めた.

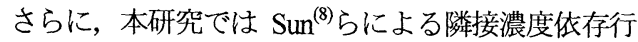
列を求め, 次項に示す画像特徴量を算出した.

3.3 画像特幑量の算出 本研究では, 式(2) (20) を利用した統計的テクスチャ解析および濃度ヒストグ ラム解析を行った. 式(2)〜(4)は, 同時濃度生起行列に よるテクスチャ特徴量であり, コントラスト $(C)$, エネ ルギ $(E)$, そしてエントロピー $(E N T)$ から構成される. 式(5)〜(8)は，濃度-ランレングス行列を用いたテクス チャ特徴量であり, 短いランの強さ $\left(S_{1}\right)$, 長いランの強

$$
\begin{aligned}
& C=\sum_{f} \sum_{g}\left\{(f-g)^{2} \cdot P(f, g)\right\} \\
& E=\sum_{f} \sum_{g}\{P(f, g)\}^{2} \\
& E N T=\sum_{f} \sum_{g}[P(f, g) \cdot \ln \{P(f, g)\}] \\
& S_{1}=\frac{\sum_{f} \sum_{l}\left\{M(f, l) / l^{2}\right\}}{\sum_{f} \sum_{l} M(f, l)} \\
& S_{2}=\frac{\sum_{f} \sum_{l}\left\{M(f, l) \cdot l^{2}\right\}}{\sum_{f} \sum_{l} M(f, l)} \\
& S_{3}=\frac{\sum_{f}\left\{\sum_{l} M(f, l)\right\}^{2}}{\sum_{f} \sum_{l} M(f, l)} \\
& S_{4}=\frac{\sum_{l}\left\{\sum_{f} M(f, l)\right\}^{2}}{\sum_{f} \sum_{l} M(f, l)} \\
& N_{l}=\frac{\sum_{f} \sum_{s}\left\{Q(f, s) / s^{2}\right\}}{\sum_{f} \sum_{s} Q(f, s)} \\
& N_{2}=\frac{\sum_{f} \sum_{s}\left\{s^{2} \cdot Q(f, s)\right\}}{\sum_{f} \sum_{s} Q(f, s)} \\
& N_{3}=\frac{\sum_{s}\left\{\sum_{f} Q(f, s)\right\}^{2}}{\sum_{f} \sum_{s} Q(f, s)} \\
& N_{4}=\frac{\sum_{f}\left\{\sum_{s} Q(f, s)\right\}^{2}}{\sum_{f} \sum_{s} Q(f, s)} \\
& N_{s}=\frac{\sum_{f} \sum_{s}\{Q(f, s)\}^{2}}{\sum_{f} \sum_{s} Q(f, s)} \\
& N_{6}=\frac{\sum_{f} \sum_{s} Q(f, s) \cdot \ln \{Q(f, s)\}}{\sum_{f} \sum_{s} Q(f, s)} \\
& \mu=\sum_{f} f \cdot P(f) \\
& \sigma^{2}=\sum_{f}(f-\mu)^{2} \cdot P(f) \\
& \sigma=\sqrt{\sum_{f}(f-\mu)^{2} \cdot P(f)} \\
& K=\frac{\sum_{f}(f-\mu)^{4} \cdot P(f)}{\sigma^{4}} \\
& S=\frac{\sum_{f}(f-\mu)^{3} \cdot P(f)}{\sigma^{3}} \\
& D s=\#\{f \mid P(f) \geq 1\}
\end{aligned}
$$

さ $\left(S_{2}\right)$, ラン濃度の一様性 $\left(S_{3}\right)$, そしてラン長さの一様 性 $\left(S_{4}\right)$ から構成される. 式(9) (14)は, 隣接濃度依存行 列によるテクスチャ特徴量であり, スモールナンバー 
の強さ $\left(N_{l}\right)$, ラージナンバーの強さ $\left(N_{2}\right)$, ナンバーの一 様性 $\left(N_{3}\right)$, 濃度の一様性 $\left(N_{4}\right)$, 二次モーメント $\left(N_{5}\right)$, そ してエントロピー $\left(N_{6}\right)$ から構成される. 式(15) (20)は, 濃度ヒストグラムを用いた画像特徴量であり, 平均 $(\mu)$, 分散 $\left(\sigma^{2}\right)$, 標準偏差 $(\sigma)$, 尖度 $(K)$, 歪度 $(S)$, そ して分布数 $(D s)$ で構成される. ただし， $P(f, g)$ は同時 濃度生起行列, $f, g$ は画素の濃度を示す. $M(f, l)$ は濃 度-ランレングス行列, $f$ は画素の濃度, l はランの長さ を示す.また, $Q(f, s)$ は隣接濃度依存行列, $f$ は画素 の濃度, $\mathrm{s}$ は任意の画素と同じ濃度を持つ画素の個数 である. $P(f)$ は濃度 $f$ の累積值を示し， \#は集合におけ る要素の数を表す.

\section{4 画像変換 ビデオマイクロスコープにより} 測定したバレル研磨面画像は, 表 4 に示す 10 種類の画 像に変換した. このときの論理積画像 : A, 論理和画 像: $\mathrm{O}$, 及び排他的論理和画像: Xの演算式を式(21) 〜 (23)に示す.

$$
\begin{aligned}
& \mathrm{A}_{x y}=\mathrm{R}_{x y} \cdot \mathrm{G}_{x y} \cdot \mathrm{B}_{x y} \\
& \mathrm{O}_{x y}=\mathrm{R}_{x y}+\mathrm{G}_{x y}+\mathrm{B}_{x y} \\
& \mathrm{X}_{x y}=\mathrm{R}_{x y} \oplus \mathrm{G}_{x y} \oplus \mathrm{B}_{x y}
\end{aligned}
$$

ここで, $\mathrm{x}, \mathrm{y}$ は画像 $(\mathrm{m}, \mathrm{n})$ 中の座標を示し, $\mathrm{R}_{\mathrm{xy}}$ は R 画像 $(m, n)$ 中の注目画素 $(x, y)$ の濃度を示寸. $\mathrm{G}_{\mathrm{xy}}, \mathrm{B}_{\mathrm{xy}}$ についても同様である.これらにより, 微妙 な光沢や色調の違いを画像特徴量に反映させる効果が 期待できる.

Table 4 Nature of transformation image data

\begin{tabular}{l|c||l|c}
\hline Image data & Code & Image data & Code \\
\hline Red & R & Hue & H \\
\hline Green & G & Value & V \\
\hline Blue & B & RGB AND & A \\
\hline Brightness & Y & RGB OR & O \\
\hline Chroma & Ch & RGB XOR & X \\
\hline
\end{tabular}

\section{4. 画像特徵量の評価}

本研究で設定した画像特徵量は, 第 3 章で示すとお り 10 種類の変換画像に対し, それぞれ 19 種類の画像 特徴量を求めたため, 合計 190 種類となる.これらの 画像特徵量候補は, 類似のものも含め, 網羅的に設定 した. その中からバレル研磨面の識別に有効な画像特 徵量を評価し，選択する必要がある. 識別を目的とし た画像特徽量は，異質な特性をもつ対象画像間でその 值の偏差が大きく, 同質な特性をもつ対象画像間でそ の值の偏差が小さいことが要求される.

本研究では, 前者の評価に対しては, 離散度(式(24)) を設定し, 後者の評価に対しては, 分布範囲および標 準偏差（式（25），(26））を設定した. 評価関数式に は, 各画像特徵量を $0 \sim 1$ の範囲で正規化した值を入力

$$
\begin{aligned}
& D=\frac{\sum_{i} d_{i}}{m} \\
& R=\frac{\sum_{i}^{m} r_{i}}{m} \\
& \text { Std }=\frac{\sum_{i}^{m} s_{i}}{m} \\
& \text { ただし } \\
& d_{i}=\frac{\sum_{\alpha}\left(\bar{x}_{i}-\bar{x}_{\alpha}\right)^{2}}{m-1}, \quad r_{i}=\max _{i}-\min _{i}, \\
& s_{i}=\sqrt{\frac{\sum_{j}\left(x_{i j}-\bar{x}_{i}\right)^{2}}{n},}, \bar{x}_{i}=\frac{\sum_{j} x_{i j}}{n} \\
& i, \alpha=1,2, \cdots, m, \quad j=1,2, \cdots, n
\end{aligned}
$$

した. ただし， $i$ 及び $\alpha$ は $m$ 個の異なるテストピース 番号を表し， $j$ はテストピースごとに測定した $n$ 枚の 画像データ番号を表す. $\max _{i}$ はテストピース $i$ の $n$ 枚 の測定画像データから得られる特徵量の最大值, $\min _{i}$ はその最小值を表す.また, $x_{i j}$ はテストピース $i$, 測定 画像データ番号 $j$ の特徽量の值を示す。

\begin{tabular}{|c|c|c|}
\hline Image data & Image features & Code \\
\hline Brightness: $Y$ & Dispersion: $\sigma^{2}$ & $Y: \sigma 2$ \\
\hline Red: R & Contrast: $\mathrm{C}$ & $\mathrm{R}: \mathrm{C}$ \\
\hline Green: G & Energy: E & $\mathrm{G}: \mathrm{E}$ \\
\hline Blue: B & Kurtosis: $\mathrm{K}$ & B:K \\
\hline \multirow[t]{2}{*}{ Value: $\mathrm{V}$} & Contrast: C & $\mathrm{V}: \mathrm{C}$ \\
\hline & Energy: E & $\mathrm{V}: \mathrm{E}$ \\
\hline \multirow[t]{7}{*}{ RGBAND: A } & Energy: $\mathrm{E}$ & A:E \\
\hline & Entropy: ENT & A:ENT \\
\hline & Grey level uniformity: S3 & A:S3 \\
\hline & Small number emphasis: N1 & A:N1 \\
\hline & Number uniformity: N3 & A:N3 \\
\hline & Entropy: N6 & A:N6 \\
\hline & Dispersion: $\sigma^{2}$ & $A: \sigma 2$ \\
\hline \multirow[t]{6}{*}{ RGB OR: O } & Contrast: C & $\mathrm{O}: \mathrm{C}$ \\
\hline & Energy: E & $O: E$ \\
\hline & Entropy: ENT & O:ENT \\
\hline & Small number emphasis: $\mathrm{N} 1$ & $\mathrm{O}: \mathrm{NI}$ \\
\hline & Number uniformity: N3 & $\mathrm{O}: \mathrm{N3}$ \\
\hline & Kurtosis: $\mathrm{K}$ & $\mathrm{O}: \mathrm{K}$ \\
\hline \multirow[t]{2}{*}{ RGB XOR: $X$} & Contrast: C & $\mathrm{X}: \mathrm{C}$ \\
\hline & Large number emphasis: $\mathrm{N} 2$ & $\mathrm{X}: \mathrm{N} 2$ \\
\hline
\end{tabular}

本研究では, 評価関数のしきい值を離散度 0.04 以上, 分布範囲 0.25 以下, 標準偏差 0.05 以下に設定し, すべ てを満たす画像特徵量を選択した。 これらのしきい值 は，NN によるバレル研磨面の識別結果をもとに実験 的に求めた適正值である. 表 5 に選択された 21 種類の 画像特徴量を示す。この結果から, 論理積, および論 理和画像から多くの画像特徴量が選択されたことがわ かる.

Table 5 Selected results of image features 


\section{5. 画像解析結果}

本章では, 本研究で評価・選択した画像特徴量によ るバレル研磨面性状の識別可能性を検討する. 図 3 (a) 及び (b) は, テストピース P-8, L-11 の測定原画像で ある.これらの研磨面は, 光沢度と表面粗さが共に非 常に近い值を示している. 従って, これらの物理量か ら表面の評価をすることは困難である.

本研究では, 全テストピースに対して各 40 サンプル の画像を測定し, その各画像特徴量を特徴量ごとに 0 〜 の範囲で正規化した. 図 3 (c) は, その正規化し た各画像特徴量のうち, テストピース P-8, L-11 の各 画像特徴量の平均值をレーダーチャートで示したもの である. 図3 (c) と同様に図 4 は, テストピース L-6, L-7 の画像特徵量抽出結果である. テストピース L-6, L-7 についても表 2 に示すように光沢度と表面粗さが それぞれ非常に近い研磨面である。これらの結果から 本研究では, 図3(c) および図 4 の画像特徴量の差異 は, 評価関数を用いてばらつきの小さい画像特徴量を 選択していることを考慮した場合, バレル研磨面性状 を識別できる可能性を有していると判断した. 同様に 他のテストピースとの比較においても，一部の画像特 徵量に識別できる可能性のある差異が確認できた。

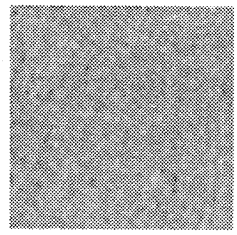

(a) Raw image of $\mathrm{P}-8$ $465.6 \%{ }^{* 1}$ $0.043 \mu \mathrm{mRa} * 2$

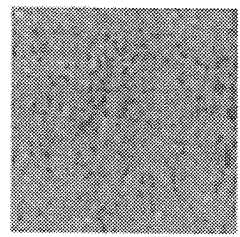

(b) Raw image of $\mathrm{L}-11$ $469.2 \% * 1$ $0.045 \mu \mathrm{mRa} * 2$
*1: Glossiness, *2: Surface roughness

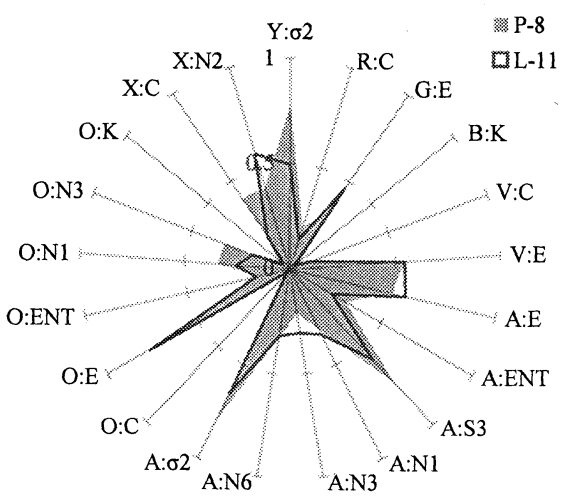

(c) Results of image analysis by radar chart

Fig.3 Examples of raw image and results of image analysis

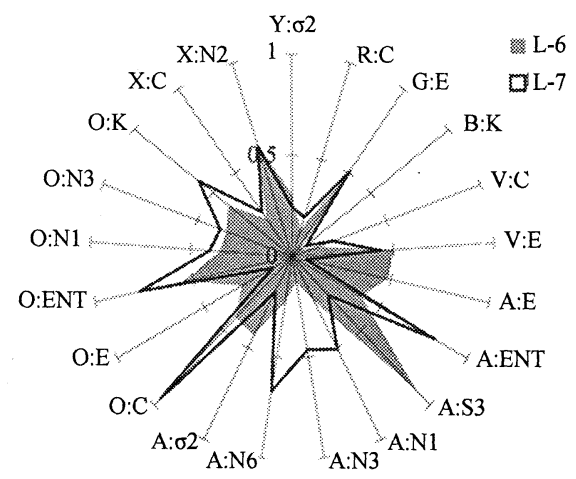

Fig.4 Results of image analysis by radar chart

\section{6. ニューラルネットワークの構築と検証結果}

本研究では，バレル研磨面の画像特徴量を利用した 識別システムとして図 5 に示す NN システムを構築し た. 本システムは, バックプロパゲーション学習ルー ルを用いた 3 層構造のネットワークであり，各層の各 ユニットにはシグモイド関数を用いた。 このシステム では, 入力データとして画像解析によって得られた 21 個の特徵量(表 5 参照)を用い, 出力データ(教師信号) として表 2 のツヤと色調の評点をもとにツヤまたは色 調のグレード (5 段階) を設定した. 学習データには, グレード評価に用いた 10 種類のテストピースに対し 各 40 サンプルの画像を測定し,その各特徴量の平均值 及び標淮偏差を $\mu, \sigma$ としたとき， $\mu, \mu \pm \sigma / 2, \mu$ $\pm \sigma$ の 5 種類の統計值を設定した. 従って, 学習デー 夕総数は, テストピース 10 種類, 特徴量 21 種類, 統 計值 5 種類の積で 1,050 となる. これらの統計值を学 習デー夕に用いたのは，そのばらつきによる認識結果 への影響を少なくするためである，中間層は，ツヤ評 価用が 36, 色調評価用が 132 のユニット数に設定する ことにより,約 2,000 回の綝返し計算で自乗誤差が 0.01 以下に収束することが認められた。表 6 は，本研究で 構筑した NN に非学習画像データを入力した検証結果 である. 各認識率右のカッコ内には，検証で用いた画 像数に対する認識画像数を示す. ツヤの平均認識率は 97.8\%，色調の平均認識率は $99.8 \%$ と高い認識率が得 られた。一方で, 光沢度の高いテストピースで誤認識 や認識不明となる傾向が僅かにみられたことは，画像 測定時の測定誤差による影響と考えられる．以上の結 果より, 本研究で提案した画像特徵量と目視評価との 対応付けが高精度に行なわれたことから, 本研究で提 案した画像特徴量が，光沢仕上げバレル研磨面の評価 に有効であることが実験的に確認された. 


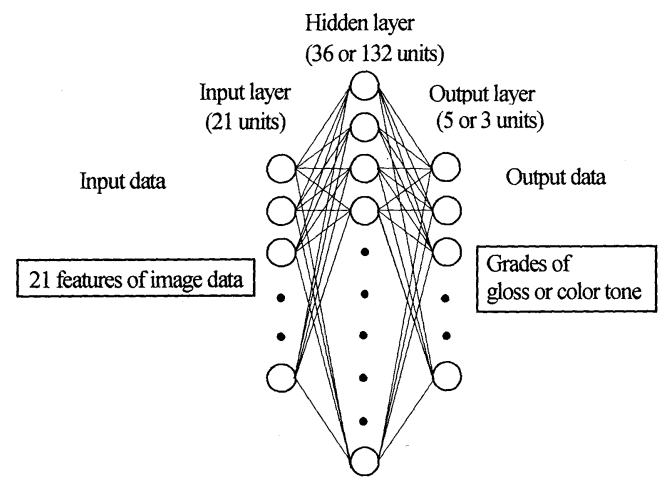

Fig.5 Neural network system for barrel finished surfaces

Table 6 Verification results of neural network for barrel finished surfaces

\begin{tabular}{|c|c|c|c|c|c|c|c|c|}
\hline \multicolumn{8}{|c|}{ (a) Grades of gloss } & (Threshold: 0.7) \\
\hline & & \multicolumn{6}{|c|}{ Grade } & \multirow{2}{*}{$\begin{array}{l}\text { Recognition } \\
\text { ratio } \%\end{array}$} \\
\hline & & 5 & 4 & 3 & 2 & 1 & unknown & \\
\hline \multirow{10}{*}{ 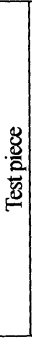 } & P-1 & 38 & 0 & 0 & 0 & 0 & 2 & $95.0(38 / 40)$ \\
\hline & P-2 & 1 & 36 & 0 & 0 & 0 & 3 & $90.0(36 / 40)$ \\
\hline & $\mathrm{P}-4$ & 0 & 37 & 0 & 0 & 0 & 3 & $92.5(37 / 40)$ \\
\hline & P-5 & 0 & 40 & 0 & 0 & 0 & 0 & $100(40 / 40)$ \\
\hline & $L-1$ & 0 & 0 & 40 & 0 & 0 & 0 & $100(40 / 40)$ \\
\hline & $\mathrm{L}-2$ & 0 & 0 & 40 & 0 & 0 & 0 & $100(40 / 40)$ \\
\hline & $L-3$ & 0 & 0 & 0 & 40 & 0 & 0 & $100(40 / 40)$ \\
\hline & $\mathrm{L}-10$ & 0 & 0 & 0 & 40 & 0 & 0 & $100(40 / 40)$ \\
\hline & L-11 & 0 & 0 & 0 & 40 & 0 & 0 & $100(40 / 40)$ \\
\hline & L-12 & 0 & 0 & 0 & 0 & 40 & 0 & $100(40 / 40)$ \\
\hline \multicolumn{8}{|c|}{ Total } & $97.8(391 / 400)$ \\
\hline
\end{tabular}

(b) Grades of color tone

(Threshold: 0.7 )

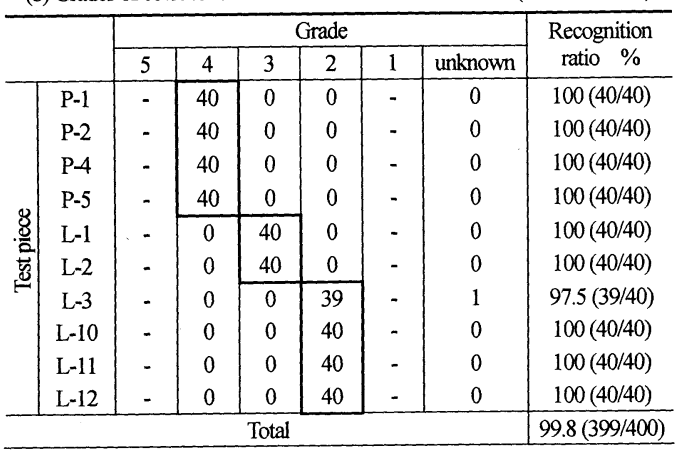

\section{7. 結言}

本研究では，従来から熟練作業者の目視に依存して いたバレル研磨面性状の評価において，画像処理およ びニューラルネットワークを利用した評洒方法を検討 した結果，以下の結論が得られた。

（1）光沢仕上げバレル研磨面画像に対し，同心フレ 一ム走查画像処理アルゴリズムを適用した統計的 テクスチャ解析および濃度ヒストグラム解析を行
い, 190 種類の画像特徵量を抽出した. そして, 離散度, 分布範囲, 標準偏差加らる特徵量評価 を行った結果, バレル研磨面性状の識別に有効な 21 種類の画像特徵量を明らかにすることができた. （2） 21 種類の画像特徵量を入力データとし，ツヤま たは色調の官能評価グレードを出力データとした ニューラルネットワークを構築した結果, コンパ ウンドの違いによる 10 種類の光沢仕上げバレル 研磨面を高い認識率でグレード評価できることが 分かった.

これらの結果から, 定性的, 主観的, 不安定だった バレル研磨面の目視評価を定量的, 客観的, 安定に行 なえる可能性が明らかとなった。 このことにより，バ レル研磨における光沢仕上げ用コンパウンドの研究開 発において有効な指標となることが期待できる.さら に, 小型ビジョンシステムを用いた高速および非接触 評価が可能であり，実用的なインライン自動検査シス テムの構築が期待できる.

\section{謝辞}

本研究にご協力いただいた，株式会社チップトンの 小林史明氏, 冨田好之氏, 千葉工業大学大学院修士修 了生の木村倫之氏に厚く感謝の意を表します.

\section{文献}

(1) Komai, K. et al., Recognition of Different Fracture Surface Morphologies Using Computer Image Processing Technique, Transactions of the Japan Society of Mechanical Engineers, Series A, Vol.57, No.542 (1991), pp.2595-2601.

(2) Huynh, V.M. et al., Texture Analysis of Rough Surface Using Optical Fourier Transform, Meas. Sci. Technol., Vol.2, No.9 (1991), pp.831-837.

(3) Mitsui, K. et al., Automatic Recognition for the Bearing of Scraped Surfaces by Image Processing Techniques, Transactions of the Japan Society of Mechanical Engineers, Series C, Vol.58, No.546 (1992), pp.626-632.

(4) Kodoh, K. et al., Analysis of Texture of Sliding Surfaces with Image Processing, Proceedings of the 46th Kyusyu Branch Regular Meeting of the Japan Society of Mechanical Engineers, (1993),pp.136-139.

(5) Kato, K. et al., Intelligent Visual Evaluation System for Mirror Finished Surfaces, Journal of the Japan Society for Precision Engineering, Vol.63, No.2 (1997), pp.208-212.

(6) Higuchi, S. et al., An Estimation of the Quality of Hairline Finished Surfaces by Applying Textural Analysis, Journal of the Japan Society for Precision Engineering, Vol.70, No.8 (2004), pp.1059-1064.

(7) Sato, S., Statistical Sensory Test Methods, JUSE Press, (1985).

(8) Sun, C. et al., Neighboring Gray Level Dependence Matrix for Texture Classification, CVGIP, Vol.23, No.3.(1983), pp.341-352. 